удК 342.7

Е. М. Якимова

Байкальский государственный университет, 2. Иркутск, Российская Федерация

\title{
КОНСТИТУЦИОННЫЕ ОСНОВЫ ТРУДОВЫХ ОТНОШЕНИЙ В СФЕРЕ ПРЕДПРИНИМАТЕЛЬСКОЙ ДЕЯТЕЛЬНОСТИ
}

\begin{abstract}
АНнотАЦия. Проблема обеспечения безопасности предпринимательской деятельности со стороны государства и общества в современной России стоит достаточно остро. Трудовые отношения должны строиться на основе учета интересов и работников, и работодателей, и государства, что позволит соблюсти баланс интересов указанных субъектов и обеспечить устойчивость экономической системы страны. Используя междисциплинарный подход, автор статьи рассматривает особенности конституционно-правового регулирования трудовых отношений в России, выделяет различные блоки вопросов, которые Конституция России обозначила как приоритетные в сфере правовой регламентации отношений в сфере труда. Сделан вывод, что амбивалетность правового регулирования трудовых отношений бесспорна, хотя приоритет защиты интересов работника очевиден, что заложило очаг напряженности и почву для конфликтов между бизнес-структурами и работниками. Усиление давления на субъекты предпринимательской деятельности в части необоснованного повышения уровня защищенности прав работников может нарушить сложившееся равновесие и поставить под угрозу устойчивость экономической системы России. кЛючЕВЫЕ словА. Трудовые отношения; труд; конституция; работник; работодатель; предпринимательская деятельность.

ИНФОРМАЦИЯ О СТАТЬЕ. Дата поступления 23 июля 2017 г.; дата принятия к печати 11 октября 2017 г.; дата онлайн-размещения 25 октября 2017 г.
\end{abstract}

Ye. M. Yakimova

Baikal State University, Irkutsk, Russian Federation

\section{CONSTITUTIONAL BASICS OF LABOUR RELATIONS IN THE SPHERE OF ENTREPRENEURIAL ACTIVITY}

\begin{abstract}
The problem of ensuring the security of entrepreneurial activity on the part of the state and society in modern Russia is quite urgent. Labour relations should be built on the basis of interests of employees, employers and the state, which will help to keep the balance of interests of the subjects specified and to ensure the stability of the country's economic system. Using an interdisciplinary approach, the author considers the specifics of the constitutional and legal regulation of labour relations in Russia, identifies various blocks of questions that are defined by the Constitution of Russia as the priorities in the sphere of legal regulation of relations in the sphere of labour. It is concluded that the ambivalency of the legal regulation of labour relations is indisputable, although the priority of the employees' protection of interests is obvious, which has induced a hotspot of tension and a ground of conflicts between the business structures and the employees. The growth of pressure on business entities in terms of the unreasonable increase of the level of the workers' rights protection can disturb the existing balance and put the stability of Russia's economic system at risk.

KEYWORDS. Labour relations; work; constitution; employee; employer; entrepreneurial activity.

ARTICLE INFO. Received July 23, 2017; accepted October 11, 2017; available online October 25, 2017.
\end{abstract}

Права и свободы являются важной составляющей концепции гармоничного развития государства и отражают «проблематизацию базовых концептов современного государства» [1, с. 218]. Устойчивость архитектуры современного госу-

(C) E. М. Якимова, 2017

\section{Baikal Research Journal}


дарства и общества невозможна без амбивалетности отношения законодателя к одному и тому же явлению. Так, свобода предпринимательской деятельности, несмотря на ее закрепление на международном и национальной уровне, не абсолютна. Как и любая свобода человека, под которой обычно понимается «самостоятельность поведения, выбора поступков и действий» [2, с. 575], а также запрет «эту свободу отрицать или ограничивать, обращенный к неопределенному кругу субъектов, обязанных уважать данную свободу, то есть практически к любому возможному нарушителю свободы» [3, с. 91], данная свобода ограничена правами других людей, интересами государства. В данной связи справедливым представляется утверждением О. А. Иванюк, что «постижение свободы с позиции правовой науки не лишено некоторой однобокости ввиду формализованного понятийно-методологического аппарата юриспруденции, но позволяет выявить рационально-организующую составляющую..., высший ценностный ориентир деятельности государственных и общественных образований» [4, с. 46]. Закрепляя свободу предпринимательской деятельности, государство лишь обозначает вектор развития, направленный на предоставление человеку возможности путем применения своего и наемного труда создать интеллектуальный или материальный продукт и реализовать его на свободном рынке товаров и услуг.

Противники предоставления гражданам свободы предпринимательской деятельности в ее крайнем варианте, когда деятельность предпринимателей практически ничем не ограничена, считают, что предприниматели будут злоупотреблять этой свободой, в том числе в трудовых отношениях с работниками, которые будут вынуждены за низкую заработную плату выполнять значительный объем работы. Стремясь получить максимальные прибыли, работодатель будет стремиться уменьшать заработную плату под любыми предлогами, что в итоге приведет к рабскому положению работника. Данную проблему прежде всего приписывают капиталистическому укладу экономики, в то время как для социалистического общества не свойственны принципы «дикого» капитализма. Стоит признать, что подобное «сгущение красок" не является воплощением реальной обстановки, хотя, безусловно, возможны ситуации злоупотребления предпринимателями своими правами по отношению к работникам, что может выразиться в использовании рабского труда, детского труда, увольнении по незаконным основаниям, выдаче «серой» заработной платы и т.п. Государственный сектор экономики данные проблемы практически не поражает в связи с большой дополнительной регламентацией трудовых отношений, что дает основание полагать, что работники в таких организациях имеют большую защиту, однако наличие свободного предпринимательства дает возможность государству существовать и активно развиваться, что обуславливает необходимость поиска консенсуса между интересами государства, предпринимателей и общества.

Стоит признать субъектов трудовых отношений прежде всего субъектами договорных отношений, что позволяет им установить возможность свободного обмена трудовыми ресурсами. Однако нельзя не учитывать важность конституционных норм и положений развивающего Конституцию законодательства в установлении основ взаимовыгодного сотрудничества работодателей (предпринимателей) и работников, поскольку данные нормы отражают баланс трудовых отношений.

Так, Конституция Российской Федерации ${ }^{1}$ регулирование трудовых отношений осуществляет по нескольким направлениям: через определение компетенции Российской Федерации и ее субъектов в регулировании трудовых отношений (п. «К» ч. 1 ст. 72), охрану труда и гарантированности со стороны государства

${ }^{1}$ Конституция Российской Федерации (принята всенародным голосованием 12 дек. 1993 г.) // Рос. газ. 1993. 25 дек.

\section{Baikal Research Journal}

электронный научный журнал Байкальского государственного университета 
определенных стандартов защиты работника (ч. 2 ст. 7, ч. 3,4 ст. 37 ), установление свободы труда и, следовательно, запрета рабского и принудительного труда (ч. 1-2 ст. 37). Кроме того, поскольку трудовые отношения тесно связаны с предпринимательской деятельностью, то опосредованно Конституция регулирует трудовые отношения через закрепление права на свободное использование своих способностей и имущества для предпринимательской и иной не запрещенной законом экономической деятельности (ч. 1 ст. 34). Наличие данного положение в конституции связано с тем, что с точки зрения цивилистического подхода и экономико-стоимостной модели труда человек продает свои способности и время работодателю за определенную плату [5]. Таким образом, Конституция России обозначает прежде всего необходимость защиты прав работников, однако говорит и о возможности применения договорных отношений в сфере труда.

Каждое из обозначенных положений Конституции России имеет сложности в преломлении относительно действующего законодательства и правоприменительной практики.

Так, принцип разграничения полномочий в федеративном государстве является основой федеративных отношений. В юридической литературе отмечается, что «решение вопросов разграничения полномочий является не только правом, но и обязанностью федерального законодателя, исходя из самой природы его компетенции и из отнесения к федеральному уровню государственной власти функций обеспечения государственного единства и территориальной целостности России, с одной стороны, и обеспечения единства стандартов и повсеместности соблюдения прав человека и гражданина на территории страны, с другой стороны» [6, с. 43]. Необходимо учитывать, что «разграничение полномочий между федеральными органами государственной власти и органами государственной власти субъектов Российской Федерации в сфере трудовых отношений и иных непосредственно связанных с ними отношений осуществляется уже не Конституцией РФ, а трудовым законодательством, а именно ст. 6 Трудового кодекса РФ» [7, с. 93].

Конституция России устанавливает возможность участия в правовом регулировании трудовых отношений как Российской Федерации, так и ее субъектов. В данной связи существуют как проблемы собственно совместного регулирования трудовых отношений, так и сложности регламентации отношений, обозначенных в ст. 72 Конституции, в целом. Так, с момента принятия ТК РФ, данный кодекс редактировался 80 раз (последний раз 18 июня 2017 г.). По информации официального сайта Государственной Думы только в 2017 году 10 поправок приняты к рассмотрению и уже проходят различные стадии законодательного процесса, что свидетельствует как о важности регламентации трудовых отношений, так и о несовершенстве трудового законодательства, отсутствии стабильной базы для развития трудовых отношений. Применительно к вопросам совместного регулирования трудовых отношений Российской Федерацией и ее субъектами это означает, что субъекты вправе участвовать в изменении федерального трудового законодательства путем предоставления заключений на законопроекты, в том числе и ТК РФ. Анализ активность субъектов по данному направлению показывает, что, несмотря на важность данной сферы в жизни общества, субъекты РФ нечасто направляют свои заключения в Государственную Думу Федерального Собрания РФ при рассмотрении законопроектов о внесении изменений в ТК РФ. Так, анализ сопроводительных документов к законопроектам по внесению изменений в ТК РФ за 2016-2017 гг. показал, что, во-первых, за этот период более чем восемь законодательных (представительных) органов государственной власти субъектов РФ никогда не предоставляли заключение (по законопроекту № 105040506 вообще был предоставлен лишь один отзыв), во-вторых, во всех без исключения заключениях

\section{Baikal Research Journal}

электронный научный журнал Байкальского государственного университета 
отсутствовали какие-либо замечания к законопроектам, законодательные (представительные) органы государственной власти субъекта ограничивались фразой следующего содержания: законопроект поддерживаем, замечаний и предложений не имеем. Иными словами, участие субъектов РФ в изменении ТК РФ сводится к формальному одобрению законопроектов. Большое количество изменений ТК РФ, которые были внесены с момента принятия рассматриваемого кодекса, свидетельствуют о проблемах с правовой регламентацией трудовых отношений. В данной связи подобный подход субъектов РФ вызывает вопросы.

Вместе с тем, представляется, что изменить данную ситуацию достаточно сложно: обязывание законодательных (представительных) органов государственной власти всех субъектов РФ предоставлять свои заключения породит лишь наличие таких же формальных 85 заключений, обязывание предоставлять отрицательные отзывы нецелесообразно, поскольку законопроект может в действительности не требовать корректировки.

Если в процессе рассмотрения проектов федеральных законов о внесении изменений в трудовое законодательство субъекты РФ принимают пассивное участие, то законодатели субъектов РФ достаточно большое внимание уделяют правовому регулированию трудовых отношений в рамках регионального законодательства. Например, активная работа ведется субъектами РФ по установлению минимального размера оплаты труда (далее - МРОТ). Процесс установления МРОТ в субъектах РФ начался давно, еще до принятия ТК РФ. Например, в г. Москва 7 декабря 2001 года был принят Закон г. Москвы № 69 «О городском минимуме оплаты труда» ${ }^{2}$. Вместе с тем, в дальнейшем он был признан противоречащим федеральному законодательству, поскольку федеральный законодатель, установив пределы регулирования по вопросам труда работников, не предоставило субъектам РФ права на определение МРОТ.

Следует оговориться, что в случае с установлением порядка минимальной заработной платы в субъектах Российской Федерации, федеральный законодатель использовал правовой механизм социального партнерства и предоставил право социальным партнерам на региональном уровне решать вопрос об установлении величины минимальной заработной платы. Итак, с 1 сентября 2007 года минимальная заработная плата в субъекте Российской Федерации устанавливается региональным соглашением с учетом социально-экономических условий и величины прожиточного минимума, установленного в субъекте Российской Федерации для трудоспособного населения. Таким образом, в настоящее время в России федеральный законодатель устанавливает возможность территориальной дифференциации МРОТ, однако нельзя не отметить, что введение более высоких гарантий по МРОТ в субъектах РФ приводит, помимо положительных моментов, в том числе и «к усугублению различий в уровне жизни регионов России» [8, с. 5].

Кроме того, органы государственной власти субъектов России не всегда соблюдают федеральное законодательство при регулировании рассматриваемых общественных отношений. Например, в региональном Соглашении «О минимальной заработной плате в Санкт-Петербурге на 2016 год»3 содержалось серьезное расхождение с определением заработной платы, которое дается в ТК РФ: стороны договорились, что для целей настоящего Соглашения в размер минимальной заработной платы не включаются компенсационные и стимулирующие выплаты. Таким образом, в Санкт-Петербурге устанавливался лишь минимальный размер

${ }^{2}$ О городском минимуме оплаты труда : закон г. Москвы от 07 дек. 2001 г. № 69 // Вестник Мэрии Москвы. 2002. № 2. (Утратил силу).

${ }^{3}$ Региональное соглашение о минимальной заработной плате в Санкт-Петербурге на 2016 год (заключено в Санкт-Петербурге 17 нояб. 2015 г.) // Петербургский дневник. 2015. 23 нояб.

\section{Baikal Research Journal}

электронный научный журнал Байкальского государственного университета 
вознаграждения за труд в зависимости от квалификации работника, сложности, количества, качества и условий выполнения работы. Подобное расхождение в содержательном наполнении понятий не основано на норме права и не может быть признано законным.

Следовательно, участие субъектов РФ в разработке трудового законодательства фрагментарно, зачастую непоследовательно: заключения на проекты изменения трудового законодательства, если вообще не предоставляются субъектами федерации, либо не содержат каких-либо замечаний, также субъекты допускают нарушение федерального законодательства. Кроме того, повышение уровня защиты работников часто связано с дополнительной нагрузкой на бюджет субъекта РФ и предпринимателей региона, что в условиях кризисных явлений в экономике и отсутствии достаточной экономической основы в субъектах РФ, приводит к невозможности обеспечить достижение обозначенного уровня.

Что касается второго блока конституционных положений, характеризующих охрану труда и гарантированность со стороны государства определенных стандартов защиты работника, то данные положений также нашли воплощения при построении композиции правового пространства в России. Первый уровень защиты трудовых прав работников установлен уже на стадии создания новых актов. Вся защита трудовых прав со всеми ее стадиями и способами входит также в механизм правового регулирования труда. Таким образом, механизмом правового регулирования труда работников является «система правовых средств, с помощью которых осуществляется упорядоченность трудовых и непосредственно связанных с ними других отношений в сфере труда в соответствии с целями и задачами правового социального государства» [9, с. 386].

Второй уровень защиты - уровень активной защиты. В данном случае защита предполагает «комплекс мероприятий, направленных на пресечение какого-либо посягательства на законные интересы, и действует непосредственно после начала посягательства как такового» [10, с. 4-5]. Стоит обратить внимание, что защита трудовых прав работников «преимущественно связана с такими формами реализации права, как использование права (в случаях самозащиты работником своих трудовых прав) и применение права (в случаях, когда работник обращается $\kappa$ компетентным органам с требованием о защите его нарушенных прав)» [10, с. 7].

Иными словами, Конституция России определяет композицию механизма охраны труда и защиты трудовых прав, которая в дальнейшем находит развитие не только в нормативных актах в сфере трудовых отношений, но и в нормах иных отраслей права (гражданском, административном процессе и т.п.).

Ч. 1 ст. 37 Конституции РФ содержит достаточно интересную формулировку: «Труд свободен. Каждый имеет право свободно распоряжаться своими способностями к труду, выбирать род деятельности и профессию», которая порождает дискуссию в научных кругах. Ведь, действительно, к данной норме, как и в иных положениях Конституции РФ, прямо право на труд и свобода труда не закреплены, или, как отмечает А. Е. Канакова, они закреплены «не традиционным способом (прямое учреждение соответствующих категорий), а посредством изложения содержания данных конституционных положений без упоминания их наименования» $[11$, с. 29], хотя «непосредственное закрепление в тексте этого права могло бы способствовать созданию наиболее эффективного механизма реализации прав и свобод в сфере труда» [12, с. 167]. Вместе с тем, представляется, что наличие правовой регламентации права на труд и свободы труда в Конституции РФ или ее отсутствие на сущность данного права в правовом пространстве не влияет, поскольку ТК РФ развивает положение Конституции и сущность этих понятий в целом раскрыл.

\section{Baikal Research Journal}

электронный научный журнал Байкальского государственного университета 
По сути, даже сама Конституция обозначает четырехэлементное содержание свободы труда: возможность человека выбирать, заниматься какой-либо незапрещенной законом трудовой деятельностью или нет отражена в положении ч. 1 ст. 37 Конституции РФ «Труд свободен»; возможность осуществления выбора по собственной инициативе определенного рода деятельности и профессии) определена в ч. 1 ст. 37 Конституции РФ: «Каждый имеет право свободно распоряжаться своими способностями к труду, выбирать род деятельности и профессию»; запрета дискриминации закреплен в ч. 3 ст. 37 Конституции РФ («...без какой бы то ни было дискриминации...»); запрет принудительного труда находит прямое отражение в ч. 2 ст. 37 Конституции РФ («Принудительный труд запрещен») [11, с. 30]. При этом право на труд можно рассматривать как закрепляемую правовыми нормами и гарантируемую государством меру возможного поведения личности в трудовых отношениях.

Вместе с тем, вопрос о свободе труда и праве на труд, подразумеваемых Конституцией России, вызывает не только споры с точки зрения конституционного закрепления, но и реальной возможности осуществления, поскольку достаточно часто различными авторами высказывается мнение о том, что право на труд в настоящее время в той или иной мере «утратило свойство всеобщности, поскольку в полной мере государством не обеспечивается» $[13$, с. 424; 14]. Доказательствами справедливости данного утверждения называют: неоправданная дифференциация в оплате труда (в частности, межотраслевая диспропорция); ограниченные гарантии, касающиеся порядка заключения и расторжения трудового договора (например, при заключении срочного трудового договора); ограниченные гарантии при определении размера оплаты труда; ограниченные гарантии при регулировании труда отдельных категорий работников (например, научно-педагогических работников).

Иными словами, конституционные основы трудовых отношений складываются на базе признания и гарантированности прав работников, во многих случаях развивающее Конституцию законодательство существенно ограничивает работодателей в трудовых отношениях. Например, в соответствии с ч. 1 ст. 261 ТК РФ расторжение трудового договора по инициативе работодателя с беременными женщинами не допускается, за исключением случаев ликвидации организации либо прекращения деятельности индивидуальным предпринимателем ${ }^{4}$. Анализ судебной практики показывает, что увольнение женщины невозможно, даже если работодатель не знал о ее беременности, даже если сама женщина не знала о своей беременности, в таких ситуациях работодатель должен восстановить женщину на работу 5 .

Подобную позицию законодателя можно рассматривать, с одной стороны, как установление элементов механизма реализации принципа социального государства, однако, с другой стороны, такая позиция тормозит развитие экономических отношений в России, поскольку вынуждает работодателя нести высокие затраты на фонд оплаты труда (не только на заработную плату, но и на различные взносы) и ограничивает экономическую мобильность в выборе персонала.

Ограничение работодателя в трудовых отношениях возможно не только ради защиты прав работников, но и в целях удовлетворении интересов государства. Примером может служить реализация конституционной обязанности лицами мужского пола по осуществлению службы по призыву. Так, в соответствии с По-

${ }^{4}$ Трудовой кодекс Российской Федерации : федер. закон от 30 дек. 2001 г. № 197-ФЗ // Рос. газ. 2001. 31 дек.

5 Решение Сыктывкарского городского суда Республики Коми от 10 мая 2016 г. по делу № 2-5717/2016. URL: www.sudrf.ru (дата обращения: 01.06.2017) ; Решение Октябрьского районного суда г. Краснодара от 15 апр. 2015 г. по делу № 2-609/2015. URL: www.sudrf.ru (дата обращения: 01.06.2017)

\section{Baikal Research Journal}

электронный научный журнал Байкальского государственного университета 
ложением о призыве на военную службу граждан Российской Федерации, утвержденным Постановлением Правительства РФ от 11 ноября 2006 г. № $663^{6}$, подлежат увольнению работники мужского пола в возрасте от 18 до 27 лет, состоящие или обязанные состоять на воинском учете и не пребывающие в запасе, в соответствии с решением призывной комиссии. Со стороны и работодатели, и работника призыв на военную службу является негативным явлением, поскольку нарушает сложившиеся между ними трудовые связи, однако установленная в Конституции России обязанность является основанием для реализации интересов государства без учета воли участников общественных отношений, в том числе и трудовых отношений.

Вместе с тем, нельзя не отметить, что в данном случае государство не в полном объеме защищает права работника. В частности, военнослужащий имеет право на предоставление органами государственной службы занятости населения в первоочередном порядке работы с учетом их специальности в государственных организациях; сохранение в течение трех месяцев после увольнения с военной службы за гражданами, работавшими до призыва (поступления) на военную службу в государственных организациях, права на поступление на работу в те же организации, а за проходившими военную службу по призыву - также права на должность не ниже занимаемой до призыва на военную службу.

Такая гарантия позволяет защитить лицо, а также корреспондируется с положением п. 1 ст. 10 Федерального закона «О статусе военнослужащих» ${ }^{7}$, что служба в армии входит в трудовой стаж. Вместе с тем, обозначенное положение указанного федерального закона представляется не в полной мере защищающим права граждан, поскольку предоставляет такое право только работникам государственный органов и организаций, то есть в данный перечень не входят даже органы местного самоуправления и муниципальные организации.

В связи с вышеизложенным предлагаем скорректировать положение п. 5 ст. 23 Федерального закона «О статусе военнослужащих», изложив ее в следующей редакции: сохранение в течение трех месяцев после увольнения с военной службы за гражданами, работавшими до призыва (поступления) на военную службу в государственных организациях, органах местного самоуправления, муниципальных организациях права на поступление на работу в те же организации, а за проходившими военную службу по призыву - также права на должность не ниже занимаемой до призыва на военную службу.

Таким образом, устанавливая общий принцип приоритета защиты прав работника перед интересами работодателя, законодатель допускает несовершенство правового регулирования даже в таких ситуациях, когда само государство вызывает прекращение трудовых отношений, что нельзя признать позитивным.

Все обозначенные выше положения Конституции и развивающего ее законодательства прямо или косвенно защищают положения прежде всего работника, все они в совокупности создают базу для дальнейшего построения механизмов взаимодействия работников и работодателей в трудовых и связанных с ними отношений. C точки зрения предпринимателей, закрепление данных прав и неукоснительная их реализация есть не что иное как вторжение государства в свободный рынок товаров и услуг. Уровень оплаты труда работника для предпринимателя зависит от того, сколько прибыли он приносит сам или сколько прибыли позволяет удержать к компании, а не от его должности. Нанимая человека на работу, предприниматель исходит чаще всего из экономической целесообразности, следовательно, расширение штата сотрудников связано с ростом бизнеса, уменьшение

${ }^{6}$ Положение о призыве на военную службу граждан Российской Федерации : утв. Постановлением Правительства РФ от 11 нояб. 2006 г. № 663 // Рос. газ. 2006. 15 дек.

${ }^{7}$ О статусе военнослужащих : федер. закон от 27 мая 1998 г. № 76-ФЗ // Рос. газ. 1998. 06 июня.

\section{Baikal Research Journal}

электронный научный журнал Байкальского государственного университета 
прибыли вызывает сокращение штата. За более чем сто лет поиска консенсуса между работодателями и работниками сделано многое как для обеспечения жизнедеятельности первых, так и предоставления гарантий вторым. Причем стоит помнить, что многие гарантии это не результат давления на работодателей, a их выбор, обусловленный здравым экономическим смыслом.

Например, в 1914 году Генри Форд стал платить рабочим невиданную по тем временам зарплату - 5 дол. в день не из доброты или веры в справедливость, он считал, что «вопрос о заработной плате еще более важен для предпринимателя, чем для рабочего. Низкая заработная плата погубит предприятие гораздо скорее, чем она погубит рабочего" [15, с. 14]. Кроме того, в 1922 году Форд решил сократить рабочую неделю до 40 часов, чтобы у работников появилось свободное время и они тратили больше денег. Иными словами, Форд принял это решение не из-за того, что хотел облегчить жизнь рабочих, а потому, что хотел повысить спрос на свои товары. В интервью журналу World's Work в 1926 году Форд объяснил, почему он заменил 48-часовую рабочую неделю на 40-часовую, сохранив зарплаты работников: «Отдых - это неотъемлемая часть растущего рынка потребления, потому что работающие люди должны иметь достаточно свободного времени, чтобы использовать потребительские товары, в том числе и автомобили» [16, с. 37].

Иными словами, конституционные положения в сфере труда должны быть сбалансированы, права работников не должны быть абсолютны, поскольку их безусловный приоритет сделает любое производство невыгодным, что принесет вред не только предпринимателю, обществу и государству, но и самому работнику, поскольку ему негде будет работать.

\section{Список использованной литературы}

1. Чуксина В. В. Права человека в контексте политико-правовой турбулентности / В. В. Чуксина, О. В. Бондаренко // Известия Байкальского государственного университета. - 2017. - Т. 27. - № 2. - С. 218-230.

2. Авакьян С. А. Конституционное право России : учеб. курс : в 2 т. / С. А. Авакьян. М. : ИНФРА-М., 2014. - Т. 1. - 863 c.

3. Стефанов А. Ю. Право и свобода: некоторые вопросы теории и философии права / А. Ю. Стефанов // Сибирский Юридический Вестник. - 2004. - № 2. - С. 91-95.

4. Иванюк О. А. Свобода совести и свобода вероисповедания: соотношение понятий и границы законодательного регулирования / О. А. Иванюк // Журнал российского права. 2010. - № 9. - C. 46-58.

5. Мухаметлатыпов Ф. У. Экономико-стоимостная модель труда: проблемы методологии и категориального анализа : учеб. пособие / Ф. У. Мухаметлапытов, У. Ф. Ибрагимов, M. Р. Богатырева. - Уфа : Изд-во Башкирского государственного университета, 2015. $272 \mathrm{c}$.

6. Собянин С. С. Правовые основы социального развития субъектов Федерации / С. С. Собянин // Журнал российского права. - 2005. - № 12. - С. 42-47.

7. Сагандыков М. С. Конституционные основы разграничения полномочий между Российской Федерацией и ее субъектами в сфере отношений, составляющих предмет трудового права // Вестник Южно-Уральского государственного университета. Серия «Право». 2013. - T. 13. - № 3. - C. 93-96.

8. Бондарева Э. С. Правовое регулирование минимальной заработной платы в субъектах Российской Федерации : монография / Э. С. Бондарева, Л. С. Гетьман, Е. Л. Иванова. Иркутск : Иркутский институт законодательства и правовой информации им. М. М. Сперанского, 2011. - $40 \mathrm{c}$.

9. Гусов К. Н. Трудовое право России : учебник / К. Н. Гусов, В. Н. Толкунова. - М. : Проспект, 2009. - 496 с.

10. Андрияхина О. М. Защита трудовых прав граждан : практ. пособие / О. М. Андрияхина, О. К. Гущина. - М. : Дашков и К, 2008. - 216 с.

\section{Baikal Research Journal}

электронный научный журнал Байкальского государственного университета 
11. Канакова А. Е. Свобода труда и право на труд в Конституции Российской Федерации: содержание и соотношение конституционных категорий / А. Е. Канакова // Алтайский юридический вестник. - 2016. - № 14. - С. 29-33.

12. Марулина А. Х. Свобода труда или право на труд: поиск оптимальной законодательной формулировки в российской конституции / А. Х. Марулина, Л. В. Петрова // Гуманитарные и юридические исследования. 2016. - № 1. - С. 165-168.

13. Федин В. В. Соотношение принципа свободы труда и права на труд / В. В. Федин // Lex Russica = Русский закон. - 2004. - T. LXIII. - № 2. - C. 411-435.

14. Трофимова Г. А. Право на труд в нормах Трудового кодекса РФ: ограниченные гарантии / Г. А. Трофимова // Российский юридический журнал. - 2014. — № 1. C. $147-155$.

15. Форд Г. Моя жизнь. Мои достижения / Г. Форд. - М. : Астрель, 2017. - 352 с.

16. Маркова П. Так говорил Генри Форд / П. Маркова. - М. : Феникс, 2016. — 64 с.

\section{References}

1. Chuksina V. V., Bondarenko O. V. Human rights in the context of political and legal turbulence. Izvestiya Baikal'skogo gosudarstvennogo universiteta $=$ Bulletin of Baikal State University, 2017, vol., 27, no 2, pp. 218-230. (In Russian).

2. Avak'yan S. A. Konstitutsionnoe pravo Rossii [The Constitutional Law of Russia: in 2 vol.]. Moscow, INFRA-M. Publ., 2014, vol., 1. 863 p.

3. Stefanov A. Yu. Law and freedom: some issues of theory and philosophy of law. Sibirskii Yuridicheskii Vestnik = Siberian Juridical Bulletin, 2004, no 2, pp. 91-95. (In Russian).

4. Ivanyuk O. A. Freedom of conscience and freedom of religion: correlation of concepts and boundaries of legislative regulation. Zhurnal rossiiskogo prava = Journal of Russian Law, 2010, no 9, pp. 46-58. (In Russian).

5. Mukhametlatypov F. U., Ibragimov U. F., Bogatyreva M. R. Ekonomiko-stoimostnaya model' truda: problemy metodologii i kategorial'nogo analiza [Economic-value model of labor: problems of methodology and categorical analysis]. Ufa, Bashkir State University Publ., 2015. $272 \mathrm{p}$.

6. Sobyanin S. S. Legal foundations of social development of federation subjects. Zhurnal rossiiskogo prava = Journal of Russian Right, 2005, no 12, pp. 42-47. (In Russian).

7. Sagandykov M. S. Constitutional basics of jurisdiction separation between the Russian Federation and its subjects in the sphere of relations that constitute the subject of labour law. Vestnik Yuzhno-Ural'skogo gosudarstvennogo universiteta. Seriya "Pravo» = Bulletin of Southern Ural State University. Series «Right», 2013, vol., 13, no 2, pp. 93-96. (In Russian).

8. Bondareva E. S., Get'man L. S., Ivanova E. L. Pravovoe regulirovanie minimal'noi zarabotnoi platy $v$ sub»ektakh Rossiiskoi Federatsii [Legal regulation of the minimum wage in constituent entities of Russian Federation]. Irkutsk Institute of legislation and legal information to them. M. M. Speransky Publ., 2011. 40 p.

9. Gusov K. N., Tolkunova V. N. Trudovoe pravo Rossii [Labor law of Russia]. Moscow Prospekt Publ., 2009. 496 p.

10. Andriyakhina O. M., Gushchina O. K. Zashchita trudovykh prav grazhdan [Protection of labour rights of citizens]. Moscow, Dashkov i K Publ., 2008. 216 p.

11. Kanakova A. E. Freedom of labour and right for work in the Constitution of the Russian Federation: content and correlation of the constitutional categories. Altaiskii yuridicheskii vestnik = Altay Juridical Bulletin, 2016, no 14, pp. 29-33. (In Russian).

12. Marulina A. Kh., Petrova L. V. Freedom of labour or right for work: search for optimal legislative statement in the Russian Constitution. Gumanitarnye $i$ yuridicheskie issledovaniya= Humanitarian and Legal Research, 2016, no 1, pp. 165-168. (In Russian).

13. Fedin V. V. Correlation of freedom of labour principle and right for work. Lex Russica= Russian Law, 2004, vol. LXIII, no 2, pp. 411-435. (In Russian).

14. Trofimova G. A. Right for work in norms of the Labor Code of the Russian Federation: limited guarantees. Rossiiskii yuridicheskii zhurnal = Russian Juridical Journal. 2014, no 1, pp. 147-155. (In Russian).

15. Ford H. Moya zhizn'. Moi dostizheniya [My Life. My Achievements] Moscow, Astrel' Publ., 2017. 352 p.

\section{Baikal Research Journal}


16. Markova P. Tak govoril Genri Ford [Thus spoke Henry Ford]. Moscow, Feniks Publ., 2016. 64 p.

\section{Информация об авторе}

Якимова Екатерина Михайловна - кандидат юридических наук, доцент, кафедра правового обеспечения национальной безопасности, Байкальский государственный университет, 664003, г. Иркутск, ул. Ленина, 11, e-mail : yakimova_katerin@mail.ru.

\section{Author}

Yekaterina M. Yakimova - PhD in Law, Associate Professor, Chair of Legal Provision of National Security, Baikal State University, 11 Lenin St., 664003, Irkutsk; e-mail : yakimova katerin@mail.ru.

\section{Для цитирования}

Якимова Е. М. Конституционные основы трудовых отношений в сфере предпринимательской деятельности / Е. М. Якимова // Baikal Research Journal. — 2017. — T. 8, № 3. DOI : $10.17150 / 2411-6262.2017 .8(3) .22$.

\section{For Citation}

Yakimova Ye. M. Constitutional basics of labour relations in the sphere of entrepreneurial activity. Baikal Research Journal, 2017, vol. 8, no. 3. DOI: 10.17150/2411-6262.2017.8(3).22. (In Russian).

\section{Baikal Research Journal}

